\title{
Metal-catalyzed Cyclizations to Pyran and Oxazine Derivatives
}

Jesús A. Varela

Carlos Saá*

Centro Singular de Investigación en Química Biolóxica e Materiais Moleculares (CIQUS) e Departamento de Químic Orgánica, Universidade de Santiago de Compostela, 15782 Santiago de Compostela, Spain

\section{carlos.saa@usc.es}

Click here to insert a dedication.

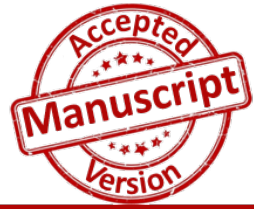

This article may be used for non-commercial purposes in accordance with Thieme Terms and Conditions for self-archiving.

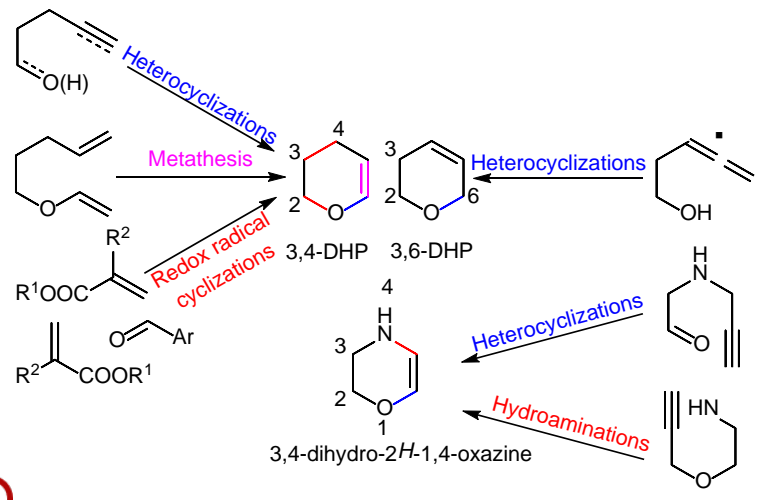

of benzofused derivatives (i.e. chromanes ${ }^{7}$ and benzoxazines ${ }^{8}$ ) have also been reported but they are not discussed here.<smiles>[Z]1C=CC=CO1</smiles>

$2 H$-pyran<smiles>[Z]C1CC=COC1</smiles>

3,4-dihydro-2 $\mathrm{H}$-pyran $(3,4-\mathrm{DHP})$<smiles>[CH]1CNC=CO1</smiles>

3,4-dihydro-2H-1,4-oxazine
3,4-Dihydropyrans

3,6-Dihydropyrans

Synthetic Applications

Summary
3,4-Dihydro-1,4-oxazines

Key words allenols, bis-homopropargyl alcohols, catalysis, cyclizations, heterocyclizations, 1,4-oxazines, pyrans, transition metals

\section{$1 \quad$ Introduction}

Heterocyclic structures, particularly six-membered oxygenated derivatives, i.e. pyrans, are prevalent units found in a wide variety of simple and sophisticated bioactive natural products. ${ }^{1}$ Over the years a great deal of effort has been devoted to these important synthetic challenges and the metal-catalyzed intramolecular addition of oxygenated nucleophiles across unsaturated carbon-carbon bonds is one of the most outstanding methods. ${ }^{2}$ This short review focuses on recent progress in metal-catalyzed intramolecular cyclizations to 3,4and 3,6-dihydropyrans (3,4-DHP and 3,6-DHP). These compounds are useful precursors for tetrahydropyrans ${ }^{3}$ and glycals, ${ }^{4}$ which are typical building blocks for carbohydrate chemistry, ${ }^{5}$ and 3,4-dihydro-1,4-oxazines, which are versatile heterocyclic motifs present in many natural products and pharmaceuticals ${ }^{6}$ (Scheme 1). Examples involving the synthesis

\section{3,4-Dihydropyrans}

3,4-Dihydropyran heterocyclic structures are readily available from metal-catalyzed intramolecular alkoxylations of terminal 4-alkyn-1-ol derivatives $(\mathrm{M}=\mathrm{W}, \mathrm{Ru}, \mathrm{Rh}) .{ }^{9}$ The cyclization involves the formation of the metal vinylidene intermediate from the alkynol, an electrophilic species at its $\alpha$ carbene carbon, and subsequent trapping with the nucleophilic hydroxyl group (Scheme 2). Hence, the cyclization process can to the alkyne (endo cyclization).

Scheme 2 Formation of 3,4-dihydropyrans by intramolecular addition of be considered as an anti-Markovnikov addition of the alcohol

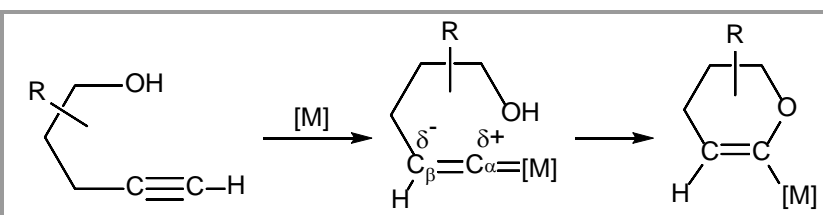




\section{alcohols to metal vinylidenes from 4-alkyn-1-ols.}

McDonald and co-workers carried out their seminal work on cyclizations of highly functionalized terminal 4-alkyn-1-ol derivatives to 3,4-dihydropyrans with catalytic $\mathrm{W}\left(\mathrm{CO}_{6}\right)$ complexes under photolytic conditions in the presence of tertiary amines (Scheme 3). ${ }^{10}$

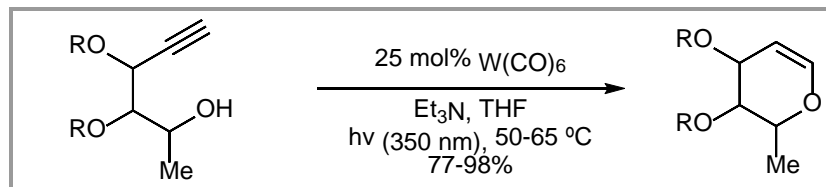

$\mathrm{R}=\mathrm{TBDMS}, \mathrm{TBDPS}$

Scheme 3 Tungsten-catalyzed formation of 3,4-dihydropyrans from bishomopropargylic alcohols.

Trost and co-workers later reported that similar cyclizations of bis-homopropargyl alcohols to 3,4-dihydropyrans can be performed in the presence of catalytic amounts of $\mathrm{CpRuCl}\left(\mathrm{PAr}_{3}\right)_{2}$ complexes that bear the electron-withdrawing ligand tris(4-fluorophenyl)phosphine (Scheme 4).11 Other ruthenium complexes bearing a tetradentate nitrogenphosphorus mixed ligand were also effective catalysts for the endo cycloisomerization of bis-homopropargyl alcohols. ${ }^{12}$

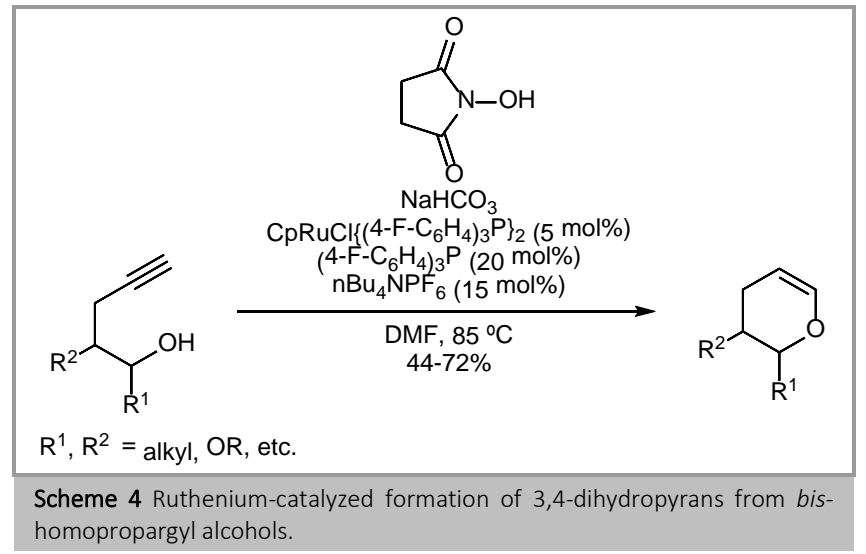

These cycloisomerization conditions proved to be chemoselective for the $O$-cyclizations over the $\mathrm{N}$-cyclizations. 3,4-Dihydropyrans were the only products obtained when 2amino-4-alkyn1-ols were exposed to the Ru-catalyzed cycloisomerization conditions (Scheme 5).13

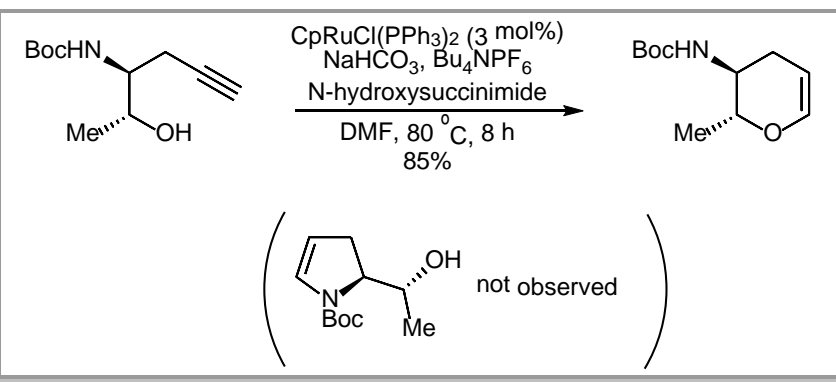

Scheme 5 Chemoselectivity of the ruthenium-catalyzed formation of 3,4dihydropyrans from 2-amino-4-alkyn-1-ols: O- vs N-cyclization.

Similar chemoselective cyclizations of 2-amino-4-alkyn-1-ols to 3,4-dihydropyrans were also achieved via rhodium vinylidene intermediates. Wilkinson's catalysts with modified electron- poor phosphines as ligands were able to form rhodium vinylidene intermediates, which were subsequently trapped by the alcohol (Scheme 6). ${ }^{14}$

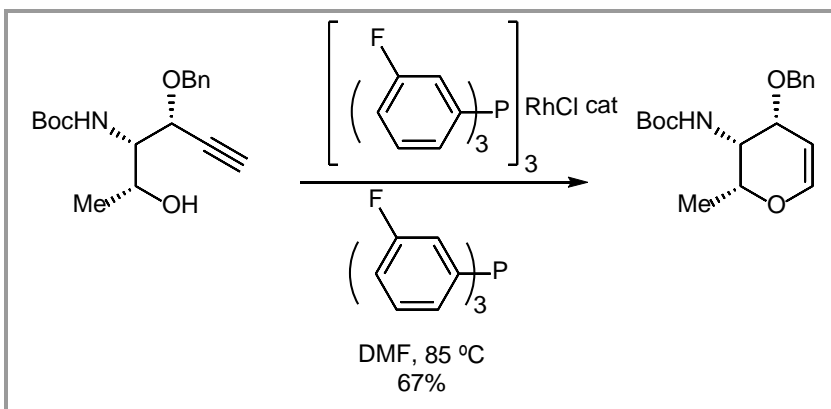

Scheme 6 Rhodium-catalyzed formation of 3,4-dihydropyrans from bishomopropargyl alcohols.

Furthermore, the reactivity of the arylpalladium intermediates obtained by oxidative addition of aryl halides to a $\operatorname{Pd}(0)$ catalyst can be tuned in order to control the catalytic arylative 5-exo and 6-endo cyclization of bis-homopropargyl alcohols. ${ }^{15}$ For instance, substrates bearing an ynamide moiety in the presence of $\operatorname{Pd}(0)$ catalyst and Xantphos as ligands mainly afforded 5,6-disubstituted-3,4-dihydropyrans, i.e., the product of 6-endo cyclization (Scheme 7).

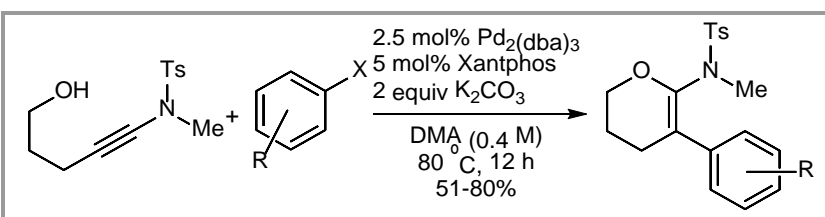

Scheme 7 Palladium-catalyzed 6-endo arylative cyclization of bishomopropargyl alcohols to 5,6-disubstituted-3,4-dihydropyrans.

In contrast, conjugated enynoates with a hydroxyl tether undergo intramolecular 6-endo-dig cyclizations to give 3,4dihydropyrans in moderate to good yields (Scheme 8).16 Addition of the hydroxyl group to the metal-coordinated alkyne followed by protonolysis is the accepted mechanistic pathway for the cyclization process. Interestingly, substituted 3,4dihydropyrans can be synthesized in one-pot by a tandem Pdcatalyzed intermolecular-intramolecular process that involves an alkynoate/alkyne coupling to give a conjugated enynoate followed by cyclization in the presence of catalytic $\mathrm{Pd}(\mathrm{OAc})_{2}$ and TDMPP [tris-(2,6-dimethoxyphenyl)phosphine].

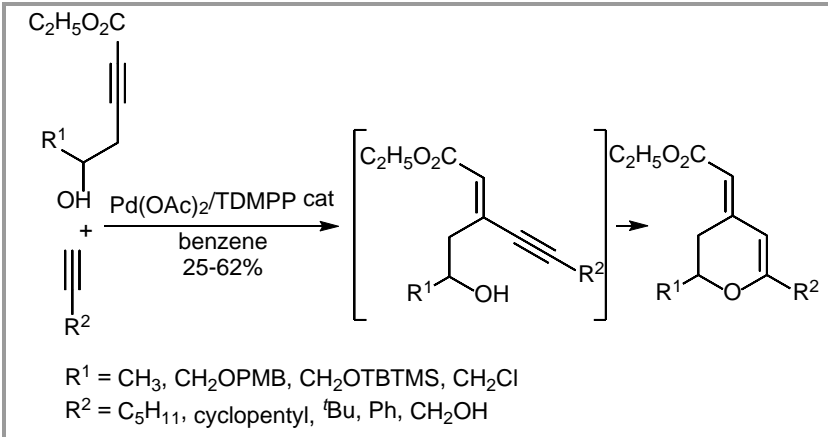

Scheme 8 Palladium-catalyzed formation of 3,4-dihydropyrans by alkyne/alkynoate coupling followed by cyclization. 
A novel Pd(II)-catalyzed oxy-carbopalladation (Wacker-Heck) process with $\beta$-hydroxy ynones also provided access to highly functionalized 2,3-dihydropyran-4-ones featuring an interesting dienic system (Scheme 9).17

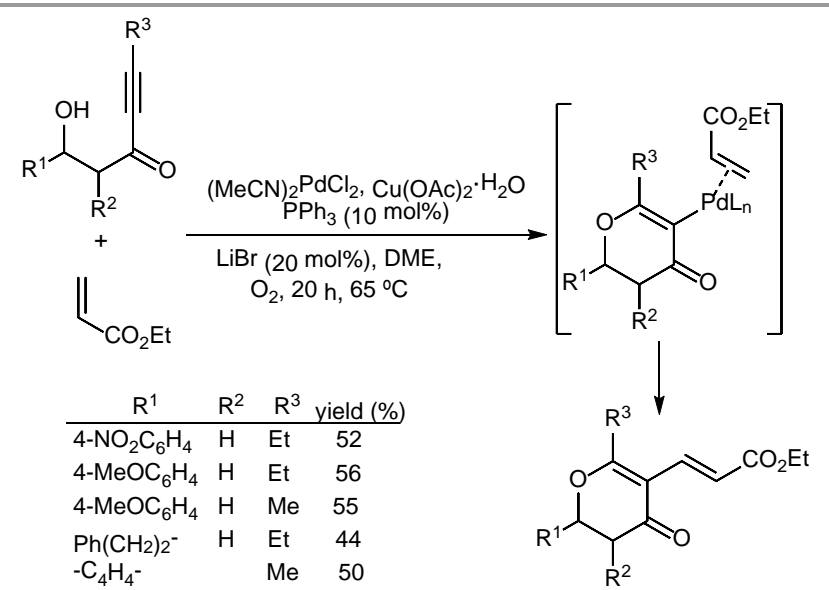

\begin{tabular}{lllc}
\multicolumn{1}{c}{$\mathrm{R}^{1}$} & $\mathrm{R}^{2}$ & $\mathrm{R}^{3}$ & yield (\% \\
\hline $4-\mathrm{NO}_{2} \mathrm{C}_{6} \mathrm{H}_{4}$ & $\mathrm{H}$ & $\mathrm{Et}$ & 52 \\
$4-\mathrm{MeOC}_{6} \mathrm{H}_{4}$ & $\mathrm{H}$ & $\mathrm{Et}$ & 56 \\
$4-\mathrm{MeOC}_{6} \mathrm{H}_{4}$ & $\mathrm{H}$ & $\mathrm{Me}$ & 55 \\
$\mathrm{Ph}\left(\mathrm{CH}_{2}\right) 2^{-}$ & $\mathrm{H}$ & Et & 44 \\
$-\mathrm{C}_{4} \mathrm{H}_{4}^{-}$ & & $\mathrm{Me}$ & 50
\end{tabular}

Scheme 9 Palladium-catalyzed formation of dihydropyranones by a cascade Wacker-Heck process.

Alternatively, 2,3-dihydropyran-4-ones can be prepared in moderate to good yields by an intramolecular palladium(II)mediated oxidative cyclization of $\beta$-hydroxyenones (Scheme 10). ${ }^{18}$

$$
\begin{aligned}
& \underset{\substack{\text { solvent, } 50^{\circ} \mathrm{C} \\
61 \%}}{\stackrel{P d \text { source, } \mathrm{O}_{2}}{\longrightarrow}} \\
& \begin{array}{clc}
\mathrm{R}^{1} & \mathrm{R}^{2} & \text { yield (\%) } \\
\hline-\left(\mathrm{CH}_{2}\right)_{2} \mathrm{Ph} & \mathrm{Me} & 79 \\
-\left(\mathrm{CH}_{2}\right)_{2} \mathrm{Ph} & \mathrm{Pr} & 76 \\
\mathrm{Ph} & \mathrm{Me} & 86 \\
\mathrm{Et} & \mathrm{Ph} & 43 \\
-\mathrm{CH}_{2} \mathrm{OBn} & \mathrm{Me} & 75 \\
\mathrm{Et} & \mathrm{Me} & 52
\end{array}
\end{aligned}
$$

Scheme 10 Palladium(II)-mediated oxidative cyclization of $\beta$-hydroxyenones to 2,3-dihydropyran-4-ones.

A novel cyclization of alkynals and alkynones to 2-vinyl-3,4dihydropyrans has recently been described. ${ }^{19}$ The mild process probably takes place by trapping of the electrophilic vinyl ruthenium carbene [generated in situ by treatment of catalytic amounts of $\mathrm{Cp} * \mathrm{RuCl}(\mathrm{cod})$ with alkynals/alkynones and (trimethylsilyl)diazomethane] with $O$-nucleophiles from the carbonyl functionalities (Scheme 11).

$$
\begin{aligned}
& \underset{\mathrm{R}^{1}}{\stackrel{\mathrm{N}_{2} \mathrm{CHTMS}}{\mathrm{R}^{2}} \underset{\mathrm{Cp}^{*} \mathrm{RuCl}(\mathrm{cod})(10 \mathrm{~mol} \%)}{\longrightarrow}} \\
& { }^{i} \mathrm{PrOH}, \mathrm{rt} \quad \mathrm{R}^{1}=\mathrm{CO}_{2} \mathrm{Me}, \mathrm{R}^{2}=\mathrm{H} ; 71 \% \\
& \mathrm{R}^{1}=\mathrm{CH}_{2} \mathrm{OBn}, \mathrm{R}^{2}=\mathrm{H} ; 80 \% \\
& \mathrm{R}^{1}=\mathrm{CH}_{2} \mathrm{OAc}, \mathrm{R}^{2}=\mathrm{H} ; 70 \% \\
& \mathrm{R}^{1}=\mathrm{CO}_{2} \mathrm{Me}, \mathrm{R}^{2}=\mathrm{Me} ; 68 \%
\end{aligned}
$$

The diastereoselectivity of the reaction was further evaluated by using 3-monosubstituted alkynals as starting materials. Alkynals bearing methoxycarbonyl, benzyloxymethyl and acetoxymethyl substituents gave rise to the corresponding 2vinyl-3,4-dihydropyrans as single cis diastereomers (Scheme 12). However, alkynals bearing bulkier 3-silyloxy substituents gave lower diastereoselectivity during the heterocyclization process.

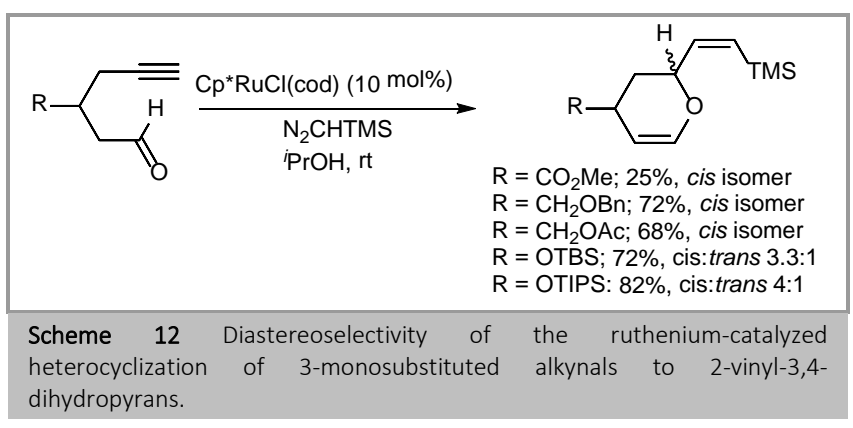

6-Substituted 2-vinyl-3,4-dihydropyrans could be obtained by ruthenium-catalyzed heterocyclization of alkynones (Scheme 13). The heterocyclization of 3-monosubstituted alkynones showed complete diastereoselectivity to give the cis 2,4,6trisubstituted 2-vinyl-3,4-dihydropyrans. Enantiomerically pure dihydropyrans could be obtained by starting from $(R)$ 3(tert-butylsilyloxy)alkynones (Scheme 13).

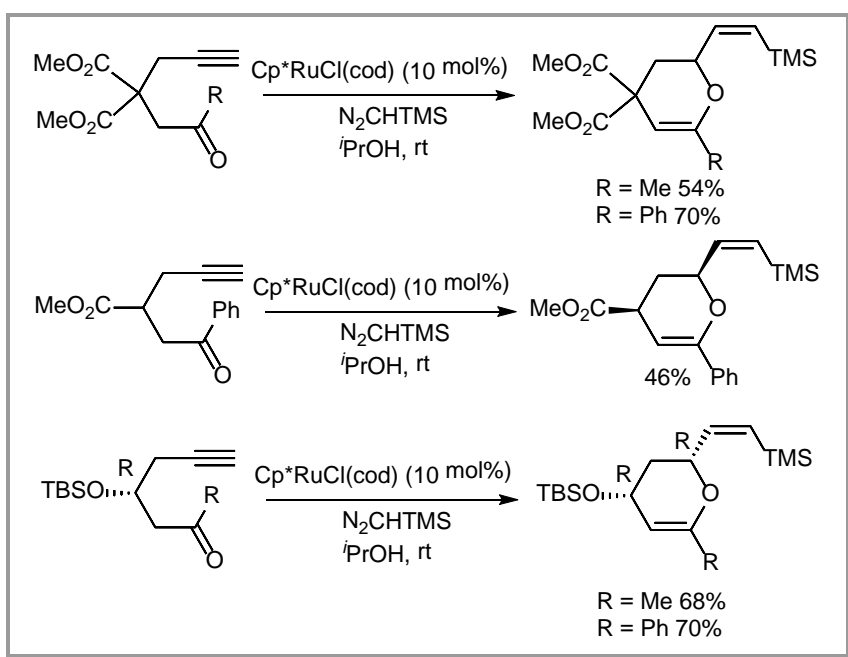

Scheme 13 Ruthenium-catalyzed heterocyclization of alkynones to 6 substituted 2-vinyl-3,4-dihydropyrans and studies of diastereoselectivity.

In addition, enantiomerically enriched 3,4-dihydropyrans are readily available by the molybdenum-catalyzed ring-closing metathesis of enol ethers. $^{20}$ The chiral Mo-alkylidene complexes efficiently undergo the dissymmetrical process in achiral enol ethers by asymmetric ring-closing metathesis to give 3,4-dihydropyrans with up to $94 \%$ ee (Scheme 14). 


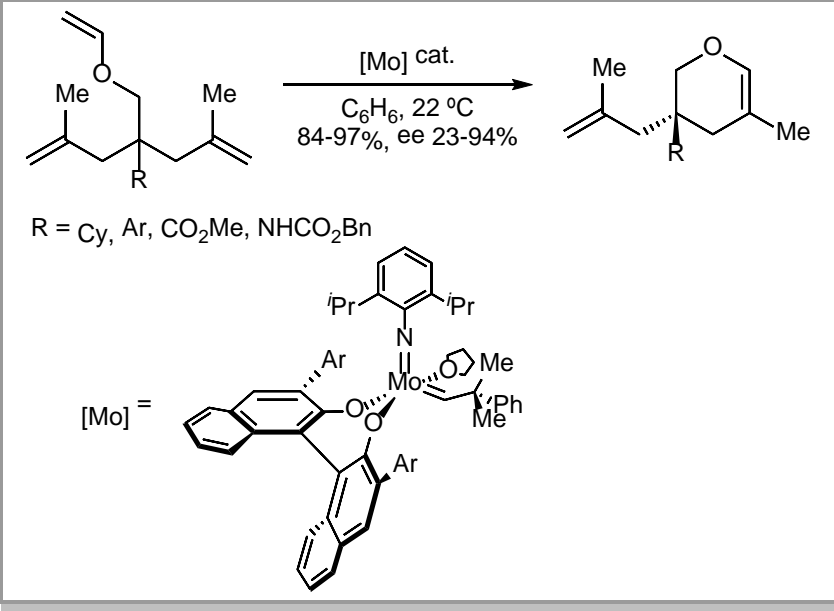

Scheme 14 Enantioselective formation of 3,4-dihydropyrans by the molybdenum-catalyzed ring-closing metathesis of enol ethers.

The diastereoselective synthesis of multifunctional 3,4dihydropyran derivatives was accomplished by a novel convergent radical cyclization of an aldehyde with two alkenes catalyzed by $\mathrm{FeCl}_{3} .{ }^{21}$ Iron-catalyzed redox radical recombinations are the processes proposed for the formation of the 3,4-dihydropyran skeleton (Scheme 15).

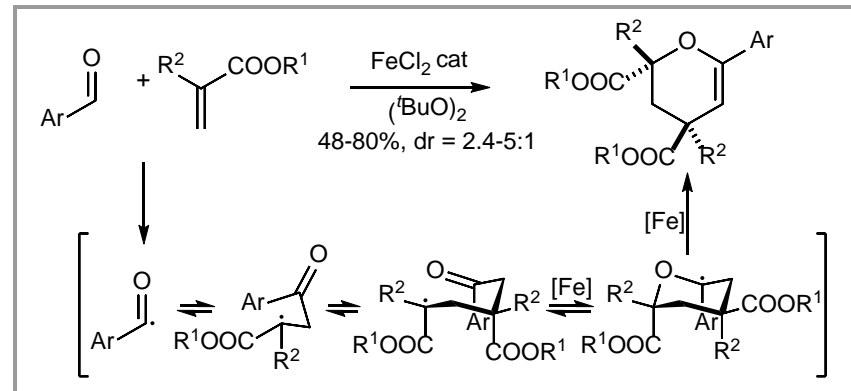

$\mathrm{R}^{1}=\mathrm{Me}, \mathrm{Et}, \mathrm{Bu},{ }^{i} \mathrm{Bu},{ }^{i} \mathrm{Pr}$, etc.

$\mathrm{R}^{2}=\mathrm{Me}, \mathrm{CH}_{2} \mathrm{COOEt}, \mathrm{CH}_{2} \mathrm{COOBu}, \mathrm{CH}_{2} \mathrm{Ph}$, etc.

Scheme 15 Iron-catalyzed redox radical diastereoselective formation of polyfunctionalized 3,4-dihydropyrans.

\section{3,4-Dihydro-1,4-oxazines}

2-Vinyl-3,4-dihydro-2H-1,4-oxazines are pivotal structures to access therapeutic agents. ${ }^{22}$ These compounds can be synthesized by Ru-catalyzed heterocyclization of $\mathrm{N}$-tethered alkynals and alkynones under the same catalytic conditions used for 2-vinyl-3,4-dihydropyrans (Scheme 11) but in this case in diethyl ether (Scheme 16). ${ }^{19}$

$$
\begin{aligned}
& \text { GP }=\mathrm{TolsO}_{2}, \mathrm{R}=\mathrm{H} ; 58 \% \\
& \mathrm{GP}=\mathrm{TisO}_{2}, \mathrm{R}=\mathrm{H} ; 57 \% \\
& \mathrm{GP}={ }^{\mathrm{t}} \mathrm{BuOCO}, \mathrm{R}=\mathrm{H} ; 58 \% \\
& \mathrm{GP}=\mathrm{BnOCO}, \mathrm{R}=\mathrm{H} ; 55 \% \\
& \mathrm{GP}=\mathrm{Ts}, \mathrm{R}=\mathrm{Ph} ; 87 \%
\end{aligned}
$$

Scheme 16 Ruthenium-catalyzed heterocyclization of $N$-tethered alkynals and alkynones to 2-vinyl-3,4-dihydro-1,4-oxazines.
Similarly, 2-exo-methylene 3,4-dihydro-1,4-oxazines can be accessed by a cooperative $\mathrm{Rh}(\mathrm{II}) / \mathrm{Br} \varnothing$ nsted acid and $\mathrm{Au}(\mathrm{I})$ catalyzed 'formal' [3+3] annulation of enal diazo ketones with $N$-propargyl anilines (Scheme 17). ${ }^{23}$ The reaction probably takes place through a 6-exo heterocyclization of a goldactivated $\mathrm{N}$-tethered alkynone generated in situ by the Rhcatalyzed reaction of enal diazo ketones with $N$-propargyl anilines (Scheme 17).

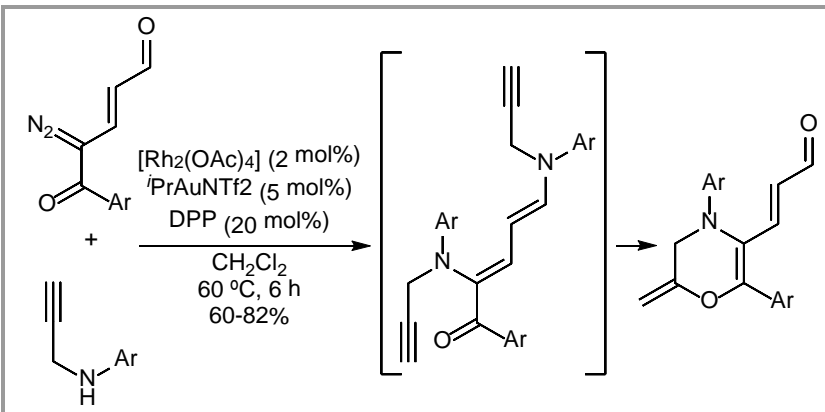

Scheme 17 3,4-Dihydro-1,4-oxazines by the cooperative Rh(II)/Brønsted acid and $\mathrm{Au}(\mathrm{I})$-catalyzed [3+3] annulation of enal diazo ketones with $\mathrm{N}$ propargyl anilines.

Rh-catalyzed transannulation of $\mathrm{N}$-sulfonyl-1,2,3-triazoles and epoxides gives rise to 3,4-dihydro-1,4-oxazines in a regioselective manner (Scheme 18). ${ }^{24}$ The mechanism probably involves the initial generation of an $\alpha$-imino rhodium(II) carbene species from the triazole followed by a 'formal' [3+3] cycloaddition with the epoxide.

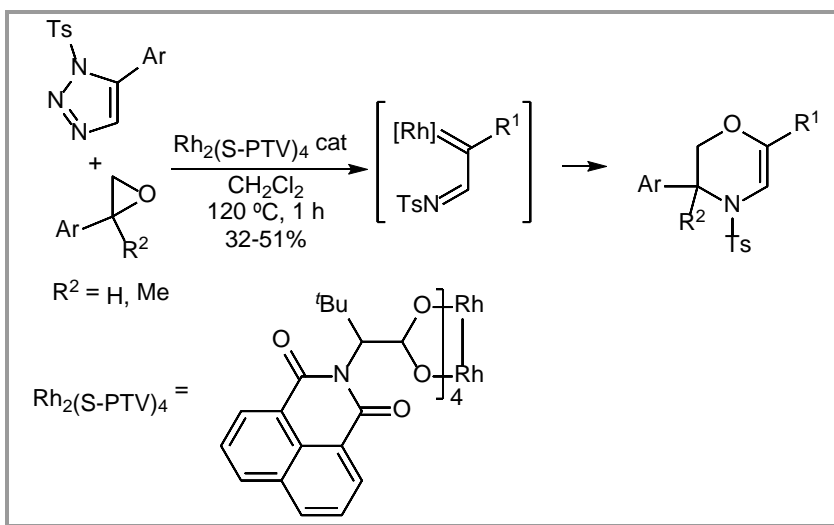

Scheme 18 Rh-catalyzed transannulation of $N$-sulfonyl-1,2,3-triazoles and epoxides to 3,4-dihydro-1,4-oxazines.

Alternatively, 3,4-dihydro-1,4-oxazines can be obtained directly by intramolecular hydroamination of alkynes. When oxygen-tethered non-activated alkynamines were reacted in the presence of the zinc-based catalyst [ $N$-isopropyl-2(isopropylamino)troponiminato]methylzinc $\left[\left({ }^{\mathrm{P} P r}\right)_{2} \mathrm{ATI}\right]-\mathrm{ZnMe}$, a smooth heterocyclization occurred to give the corresponding 3,4-dihydro-1,4-oxazines by an intramolecular hydroamination (Scheme 19). ${ }^{25}$ 


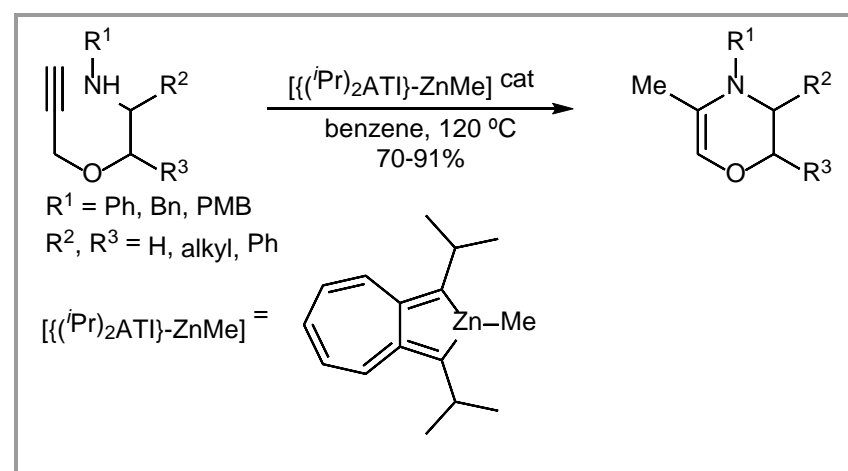

Scheme $19 \mathrm{Zn}$-catalyzed intramolecular hydroamination of alkynylamines to 3,4-dihydro-1,4-oxazines.

\section{$4 \quad$ 3,6-Dihydropyrans}

Catalytic asymmetric Wacker-type cyclization of alkenyl alcohols promoted by the Pd-SPRIX catalyst afforded 3,6dihydropyrans through a 6-endo nucleophilic attack of the hydroxyl group to the metal-activated olefin. The use of a trisubstituted double bond ensured the exclusive formation of the 3,6-dihydropyran isomer by $\beta$-hydride elimination of the Pd complex intermediate (Scheme 20). ${ }^{26}$

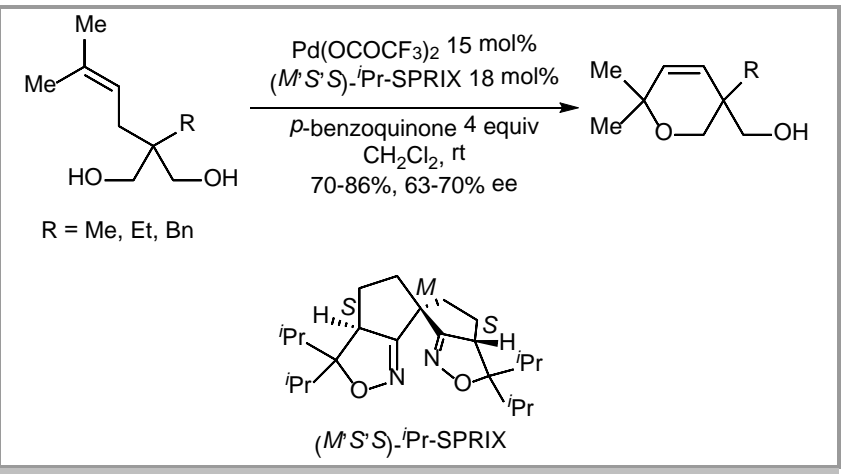

Scheme 20 Palladium-catalyzed asymmetric Wacker-type cyclization of alkenyl alcohols to 3,6-dihydropyrans.

Allenols are also useful starting materials for the synthesis of simple and chiral 3,6-dihydropyrans. Electrophilic activation of the allene by $\mathrm{Au}(\mathrm{I})$ or $\mathrm{Au}(\mathrm{III})$ catalysts in chiral 3-allenols afforded 3,6-dihydropyrans through a 6-endo cycloisomerization with axis-to-center chirality transfer (Scheme 21, eq 1).27 Similarly, 3-hydroxy-1,5-allenynes were chemoselectively transformed into the corresponding 2ethynyl-3,6-dihydropyrans by the preferential $\mathrm{Au}(\mathrm{I})$-catalyzed activation of the allene over the alkyne functionality (Scheme 21, eq 2). Interestingly, reverse chemoselectivity can be achieved using a platinum catalyst. ${ }^{28}$

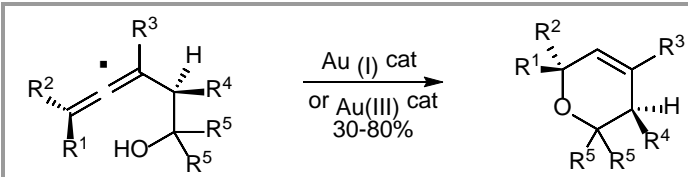

$\mathrm{R}^{1}=\mathrm{H},{ }^{t} \mathrm{Bu}, \mathrm{Me}$

$\mathrm{R}^{2}=\mathrm{H}, \mathrm{Me},{ }^{n_{\mathrm{Bu}},{ }^{\mathrm{t}} \mathrm{Bu}, \mathrm{Ph}}$

$\mathrm{R}^{3}=\mathrm{H}, \mathrm{Me}$

$\mathrm{R}^{4}=\mathrm{H}$, COOEt, OAc, OMe

$\mathrm{R}^{5}=\mathrm{H}, \mathrm{Me}$

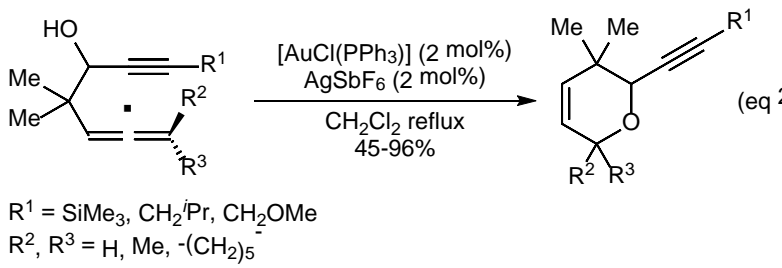

Scheme 21 Gold-catalyzed 6-endo cyclization of 3-allenols to 3,6dihydropyrans.

Enantiopure 3,6-dihydropyrans could also be prepared by chemo-, regio-, and stereocontrolled Au(III)-, Pt(II)- or Pd(II)catalyzed 6-endo cyclization of $\beta$-allenols and $\beta, \gamma$-allenediols derived from D-glyceraldehyde. ${ }^{29}$ In all cases the metalcatalyzed 6-endo cycloisomerization is initiated by chemo- and regiospecific attack of the secondary hydroxyl group at the terminal allene carbon atom of $\beta, \gamma$-allenediols to give the corresponding 3,6-dihydropyran (Scheme 22). Moreover, tandem Pd- and Pt-catalyzed cyclization/coupling reactions of 3 -allenols with allyl bromide and ylides gave rise to enantiopure functionalized tri- and tetrasubstituted 3,6dihydropyrans (Scheme 22).29b 


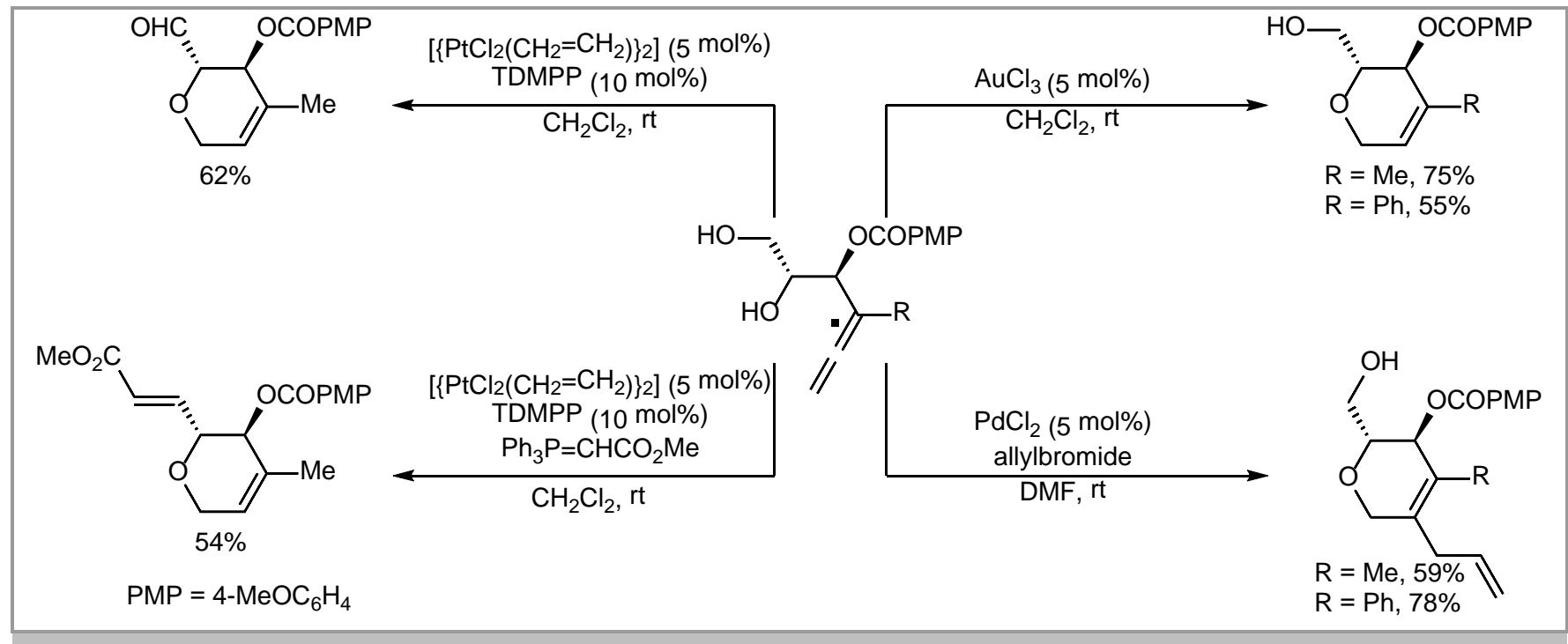

Scheme 22 Chemo-, regio-, and stereocontrolled metal-catalyzed formation of enantiopure 3,6-dihydropyrans from $\beta, \gamma$-allenediols.

Bicyclic 3,6-dihydropyrans (4,6-dihydro-furo-[3,4-c]-pyrans) can be accessed from substituted dipropargyl ethers by means of two consecutive carbopalladations initiated by a 'formal' anti-carbopalladation of a non-activated alkyne. The second carbopalladation step involves the formation of the dihydropyran ring (Scheme 23). ${ }^{30}$ Mechanistically, when tertiary propargylic alcohols were mixed with aryl iodides in the presence of $\mathrm{Pd}(\mathrm{II})$ catalysts, the syn-carbopalladation occurred and the Pd was placed $\alpha$ to the oxygen. If no other reaction pathways are available (e.g., $\beta$-hydrogens are not present), the cis-trans isomerization of the transient vinyl Pd complex will occur to give the second carbopalladation on the remaining alkyne.

When substituted propargyl allyl ethers are used as substrates (tertiary propargylic $\omega$-enynols), the cyclization process that leads to 3,6-dihydropyrans would involve a 'formal' anticarbopalladation followed by a Mizoroki-Heck reaction (Scheme 24). Interestingly, the geometry of the double bond in the final product is dependent on the geometry of the starting substrate, which would exclude carbocationic intermediates as these would lead to $E / Z$ mixtures.

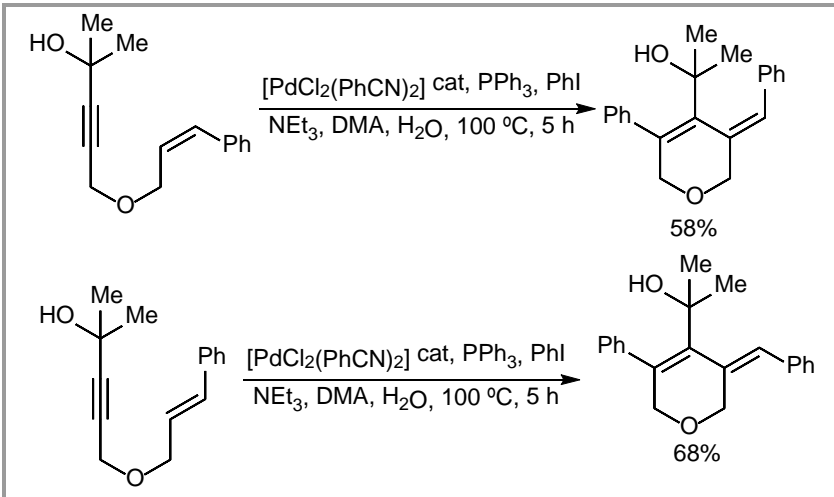

Scheme 24 3-Exo-benzylidene 3,6-dihydropyrans by tandem 'formal' anticarbopalladation followed by Mizoroki-Heck reactions.

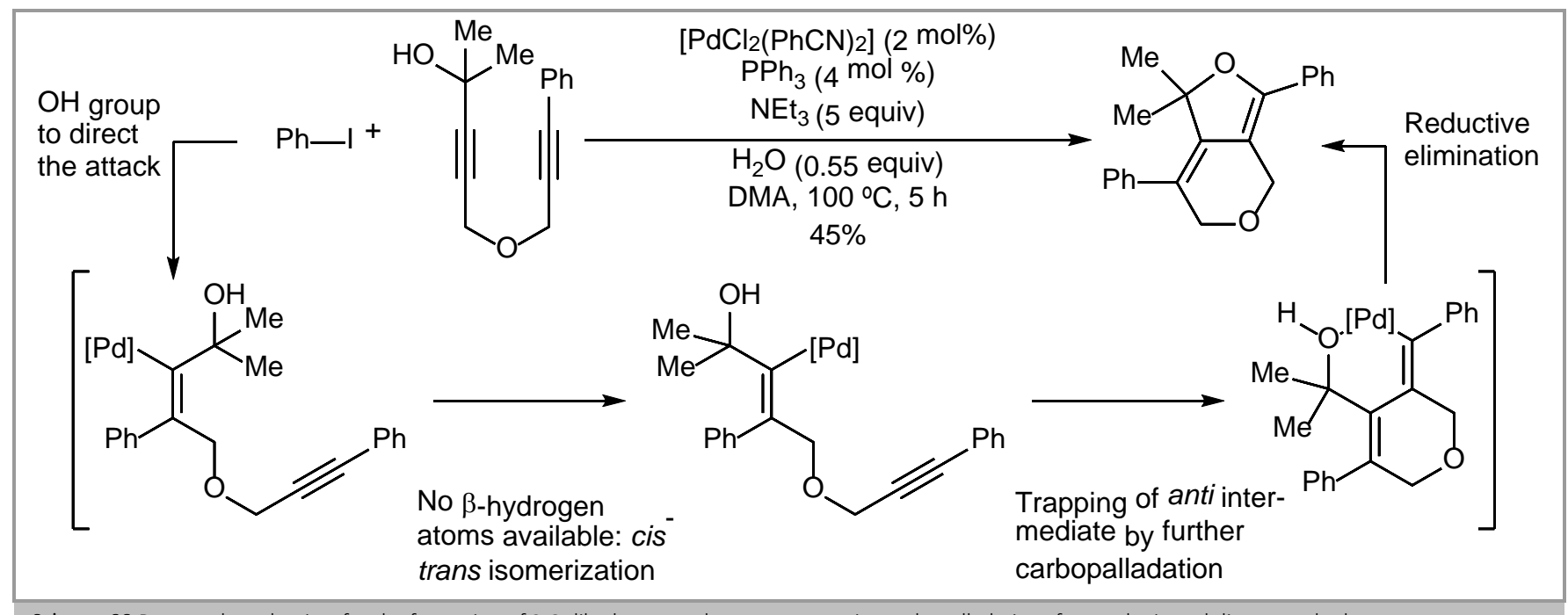

Scheme 23 Proposed mechanism for the formation of 3,6-dihydropyrans by two consecutive carbopalladations from substituted dipropargyl ethers. 


\section{5}

Synthetic Applications

As stated in the Introduction, pyran structures and, more specifically, 3,4- and 3,6-dihydropyrans are relevant units found in many bioactive natural products. In this section, remarkable synthetic approaches are briefly mentioned to highlight the synthetic method used. For the assembly of ring A of Miyakolide, a macrolide isolated from a sponge of the genus Polyfibrospongia, a Pd-catalyzed tandem alkynoate/alkyne coupling followed by 6-endo cyclization was selected to obtain the exo-methylene 3,4-dihydropyran precursor (Scheme 25).16 The bioassay results for the macrolide showed potent in vitro and in vivo antitumor activity against A-549 human lung carcinoma and B-16 melanoma, respectively. ${ }^{31}$

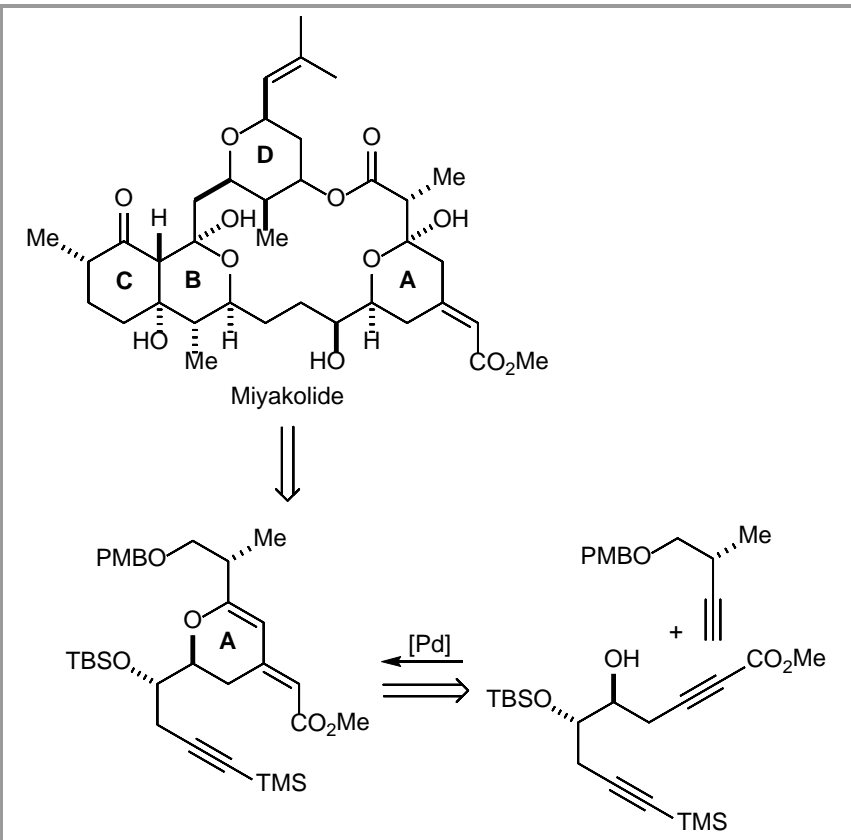

Scheme 25 Retrosynthetic plan for the formation or ring A of Miyakolide.

The same methodology was used to assemble ring $\mathrm{C}$ in the synthetic approach to Bryostatins, a family of structurally complicated macrolides that exhibit an exceptional range of biological activities (Scheme 26). ${ }^{32}$

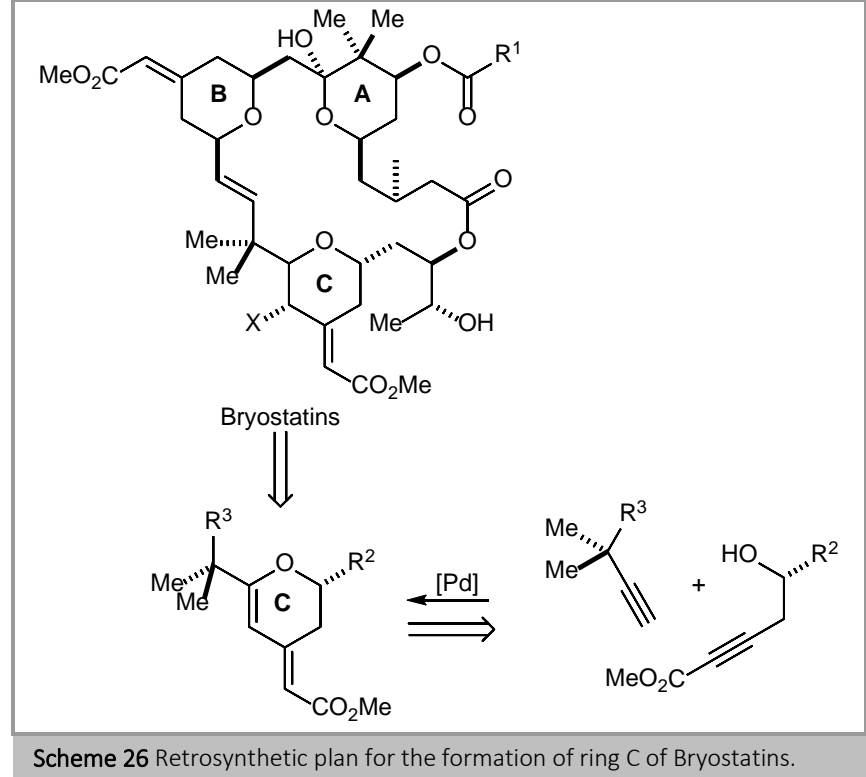

For the synthesis of ring $E$ of several indole alkaloids such as (+)-6-oxoalstophylline, (-)-alstophylline and (-)-alstonerine, a modified Pd-catalyzed Wacker sequence was applied to generate rapidly the cis-fused 3,4-dihydropyranyl enone (Scheme 27). ${ }^{33}$ For more details of the oxidative Wacker cyclization see the comments and details in Scheme 9.

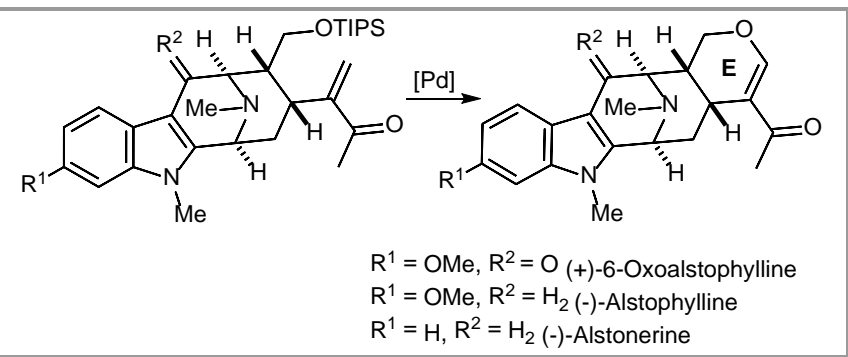

Scheme 27 Formation of the cis-fused 3,4-dihydropyranyl ring of indole alkaloids by palladium oxidative cyclization.

Bejarol metabolites are terpenoids that are found in plants of $S$. oblongifolia and they contain a substituted 3,6-dihydropyran ring with three stereocenters. The first diastereo- and enantiolesective total synthesis of $(3 R, 5 R, 9 R)$-bejarol and its $(3 R, 5 S, 9 R)$-isomer was accomplished using the Au-catalyzed 6endo cyclization of an enantiomerically pure $\beta$-allenol as the key step (Scheme 28). ${ }^{34}$ 


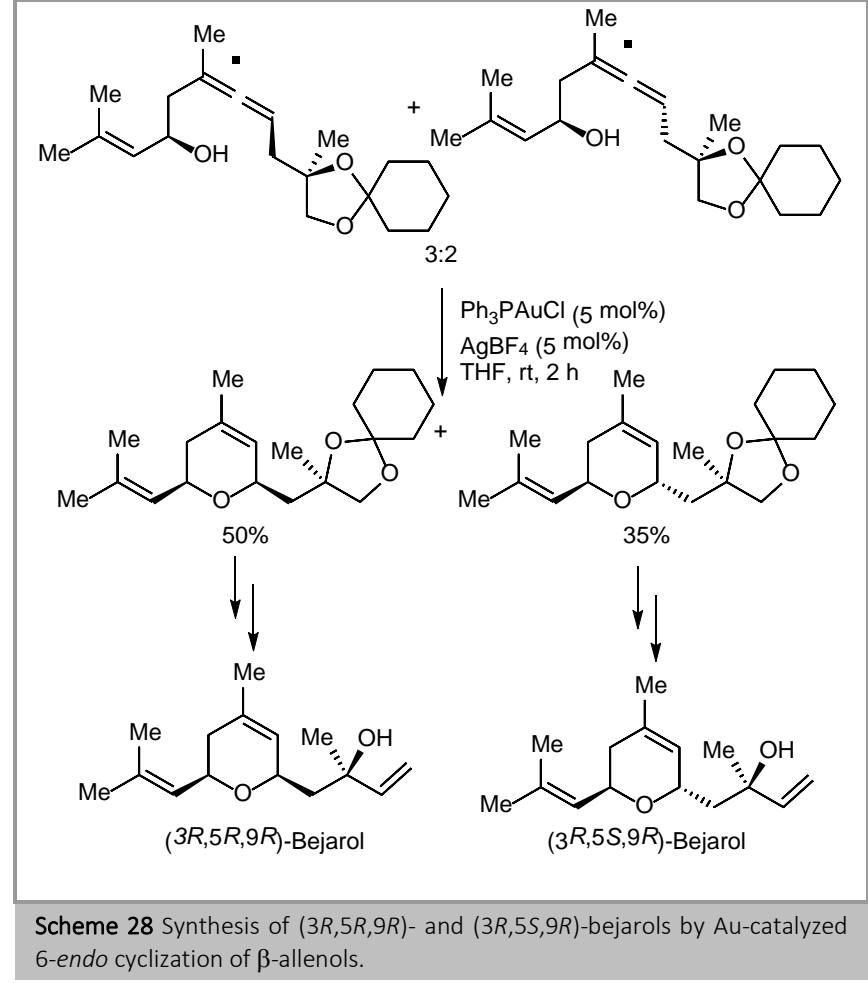

\section{6}

\section{Summary}

Partially hydrogenated pyran derivatives, 3,4- and 3,6dihydropyrans, and 3,4-dihydro-1,4-oxazines are key synthetic precursors for scaffolds present in numerous natural products with relevant biological activities. Metal-catalyzed intramolecular cyclizations are highly effective for the synthesis of these heterocyclic systems. In the examples discussed, the formation of an electrophilic species by activation of the alkyne functionality (vinylidenes, vinyl carbenes, etc.) of bishomopropargyl alcohol and derivatives with metals $(\mathrm{W}, \mathrm{Rh}, \mathrm{Ru}$, Pd) followed by trapping with oxygen nucleophiles (heterocyclizations) has been the main approach to obtain the 3,4-dihydropyran nucleus. Neutral processes (ring-closing metathesis) and redox radical cyclizations with carbon-carbon and carbon-oxygen bond formation, respectively, represent attractive synthetic approaches to achieve the stereoselective formation of 3,4-dihydropyrans. Analogously, the 3,4-dihydro1,4-oxazine nucleus can be obtained by electrophilic activation of alkynes in $N$-tethered alkynals or oxygen-tethered alkynamines followed by trapping with oxygen or nitrogen (hydroamination) nucleophiles, respectively. Similarly, electrophilic activation of alkenyl alcohols and allenols followed by intramolecular nucleophilic trapping allows the stereoselective formation of 3,6-dihydropyrans. Substituted mono- and bicyclic 3-benzylidene 3,6-dihydropyrans could be assembled by two consecutive carbopalladations (carboncarbon bond formation). Remarkable applications in the synthesis of natural products are highlighted. We believe that further novel protocols will be developed in the future and that these will enable the synthesis of structurally challenging and bioactive natural products.

\section{Acknowledgment}

This work was supported by the Spanish MINECO (project CTQ201459015R), the Xunta de Galicia (project GRC2014/032) and the European Regional Development Fund (projects CTQ2014-59015R and GRC2014/032). We also thank the ORFEO-CINQA network (CTQ201451912REDC).

\section{Biosketches}

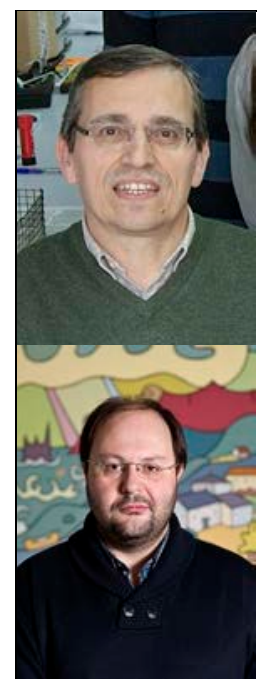

Carlos Saá (top), born in Lugo, Spain, studied chemistry at the University of Santiago de Compostela, Spain, where he received his PhD in 1985. He spent two-year (1987-1988) as a NATO postdoctoral research associate at the University of California, Berkeley, working with Prof. K. P. C. Vollhardt. Since 1990 he joined the Department of Organic Chemistry University of Santiago de Compostela, Spain, as Associate Professor, and since 2004 as a full Professor. His research interest centers on the discovery of new reactivity using organometallic catalysts.

Jesús A. Varela (bottom) was born in 1971 in Lugo, Spain, and studied chemistry at the University of Santiago de Compostela, Spain. He completed his M. Sc. in 1994 and his Ph. D. thesis in 1999 (excellent award) both under the supervision of Prof. Dr. Carlos Saá. He spent a predoctoral research training period in Harvard University in 1997 under supervision of Prof. Dr. Matthew Shair. From 1999 to 2001, he spent a postdoctoral period as an Alexander Von Humboldt and Marie Curie Fellow with Prof. Dr. Paul Knochel at Ludwig Maximilians Universität in Munich, Germany. He joined the Department of Organic Chemistry, University of Santiago de Compostela as Ramón y Cajal researcher, and since 2008 as Associate Professor. His research interests are focused in discovery new organometallic catalyzed reactions.

\section{References}

(1) (a) Fravel, B. W., Pyrans and their Benzo Derivatives: Applications. In Comprehensive Heterocyclic Chemistry III,
Katritzky, A. R.; Ramsden, C. A.; Scriven, E. F. V.; Taylor, R. J. K., Eds. Elsevier: Dordrecht, 2008; Vol. 7, pp 701. (b) Elliott, M. C. J. Chem. Soc., Perkin Trans. 1 2002, 2301. (c) Elliott, M. C.; Williams, E. J. Chem. Soc., Perkin Trans. 1 2001, 2303. (d) Elliott, M. C. J. Chem. Soc., Perkin Trans. 1 2000, 1291. (e) 
Mitchinson, A.; Nadin, A. J. Chem. Soc., Perkin Trans. 1 2000, 2862. (f) Boivin, T. L. B. Tetrahedron 1987, 43, 3309.

(2) (a) Kurahashi, T.; Matsubara, S. Acc. Chem. Res. 2015, 48, 1703. (b) Cornil, J.; Gonnard, L.; Bensoussan, C.; Serra-Muns, A.; Gnamm, C.; Commandeur, C.; Commandeur, M.; Reymond, S.; Guerinot, A.; Cossy, J. Acc. Chem. Res. 2015, 48, 761. (c) Synthesis of Heterocycles via Metal-Catalyzed Reactions that Generate One or More Carbon-Heteroatom Bonds. John P. Wolfe ed.; Springer: Heidelberg, New York, Dordrecht, London, 2013. (d) Alcaide, B.; Almendros, P.; Alonso, J. M. Org. Biomol. Chem. 2011, 9, 4405. (e) Hintermann, L. Top. Organomet. Chem. 2010, 31, 123. (f) Larrosa, I.; Romea, P.; Urpí, F. Tetrahedron 2008, 64, 2683. (g) Alonso, F.; Beletskaya, I. P.; Yus, M. Chem. Rev. 2004, 104, 3079. (h) Beller, M.; Seayad, J.; Tillack, A.; Jiao, H. Angew. Chem. Int. Ed. 2004, 43, 3368.

(3) Clarke, P. A., Tetrahedron. ed.; 2011; Vol. 67, p 4949.

(4) (a) Smoot, J. T.; Demchenko, A. V. Adv. Carbohydr. Chem. Biochem. 2009, 62, 161. (b) Boltje, T. J.; Buskas, T.; Boons, G.J. Nat. Chem. 2009, 1, 611. (c) Schmidt, R. R.; Vankar, Y. D. Acc. Chem. Res. 2008, 41, 1059. (d) Ramesh, N. G.; Balasubramanian, K. K. Eur. J. Org. Chem. 2003, 4477. (e) Seeberger, P. H.; Bilodeau, M. T.; Danishefsky, S. J. Aldrichimica Acta 1997, 30, 75.

(5) (a) Yu, B.; Wang, L.-X.; Danishefsky, S.; Crich, D., Carbohydrate Synthesis towards Glycobiology. Ding, K.; Dai, L.-X., Eds. Wiley-VCH: Weinheim, 2012. (b) Nicolaou, K. C.; Mitchell, H. J. Angew. Chem. Int. Ed. 2001, 40, 1576. (c) Sears, P.; Wong, C.-H. Science 2001, 291, 2344.

(6) (a) Taylor, R. D.; MacCoss, M.; Lawson, A. D. G. J. Med. Chem. 2014, 57, 5845. (b) Fox, B. M.; Sugimoto, K.; Iio, K.; Yoshida, A.; Zhang, J.; Li, K.; Hao, X.; Labelle, M.; Smith, M.-L.; Rubenstein, S. M.; Ye, G.; McMinn, D.; Jackson, S.; Choi, R.; Shan, B.; Ma, J.; Miao, S.; Matsui, T.; Ogawa, N.; Suzuki, M.; Kobayashi, A.; Ozeki, H.; Okuma, C.; Ishii, Y.; Tomimoto, D.; Furakawa, N.; Tanaka, M.; Matsushita, M.; Takahashi, M.; Inaba, T.; Sagawa, S.; Kayser, F. J. Med. Chem. 2014, 57, 3464. (c) Matralis, A. N.; Kourounakis, A. P. J. Med. Chem. 2014, 57, 2568. (d) Li, W.; Duan, X.; Yan, H.; Xin, H. Org. Biomol. Chem. 2013, 11, 4546. (e) Kourounakis, A. P.; Charitos, C.; Rekka, E. A.; Kourounakis, P. N. J. Med. Chem. 2008, 51, 5861.

(7) Varela-Fernández, A.; González-Rodríguez, C.; Varela, J. A.; Castedo, L.; Saá, C. Org. Lett. 2009, 11, 5350.

(8) (a) Thansandote, P.; Chong, E.; Feldmann, K.-O.; Lautens, M. J. Org. Chem. 2010, 75, 3495. (b) Kundu, N. G.; Chaudhuri, G.; Upadhyay, A. J. Org. Chem. 2001, 66, 20.

(9) (a) Varela, J. A.; González-Rodríguez, C.; Saá, C. Top. Organomet. Chem. 2014, 48, 237. (b) Trost, B. M.; McClory, A. Chem.-Asian J. 2008, 3, 164. (c) Metal Vinylidenes and Allenylidenes in Catalysis: From Reactivity to Applications in Synthesis. Bruneau, C.; Dixneuf, P., Eds. Wiley-VCH: Weinheim, 2008. (d) Bruneau, C.; Dixneuf, P. H. Angew. Chem. Int. Ed. 2006, 45, 2176.

(10)(a) McDonald, F. E.; Reddy, K. S. J. Organomet. Chem. 2001, 617-618, 444. (b) McDonald, F. E.; Reddy, K. S.; Díaz, Y. J. Am. Chem. Soc. 2000, 122, 4304. (c) McDonald, F. E. Chem.-Eur. J. 1999, 5, 3103.

(11)Trost, B. M.; Rhee, Y. H. J. Am. Chem. Soc. 2002, 124, 2528.
(12)Liu, P. N.; Su, F. H.; Wen, T. B.; Sung, H. H. Y.; Williams, I. D.; Jia, G. Chem.-Eur. J. 2010, 16, 7889.

(13)Zacuto, M. J.; Tomita, D.; Pirzada, Z.; Xu, F. Org. Lett. 2010, 12, 684.

(14)Trost, B. M.; Rhee, Y. H. J. Am. Chem. Soc. 2003, 125, 7482.

(15)Fujino, D.; Yorimitsu, H.; Osuka, A. J. Am. Chem. Soc. 2014 136, 6255.

(16)Trost, B. M.; Frontier, A. J. J. Am. Chem. Soc. 2000, 122, 11727.

(17)Silva, F.; Reiter, M.; Mills-Webb, R.; Sawicki, M.; Klar, D.; Bensel, N.; Wagner, A.; Gouverneur, V. J. Org. Chem. 2006, 71, 8390.

(18)(a) Baker-Glenn, C.; Hodnett, N.; Reiter, M.; Ropp, S.; Ancliff, R.; Gouverneur, V. J. Am. Chem. Soc. 2005, 127, 1481. (b) Reiter, M.; Turner, H.; Mills-Webb, R.; Gouverneur, V. J. Org. Chem. 2005, 70, 8478. (c) Reiter, M.; Ropp, S.; Gouverneur, V. Org. Lett. 2004, 6, 91.

(19)Cambeiro, F.; Lopez, S.; Varela, J. A.; Saa, C. Angew. Chem. Int. Ed. 2014, 53, 5959.

(20)Lee, A. L.; Malcolmson, S. J.; Puglisi, A.; Schrock, R. R.; Hoveyda, A. H. J. Am. Chem. Soc. 2006, 128, 5153.

(21)Lv, L.; Xi, H.; Bai, X.; Li, Z. Org. Lett. 2015, 17, 4324.

(22)(a) Bogacki, R.; Gill, D. M.; Kerr, W. J.; Lamont, S.; Parkinson, J. A.; Paterson, L. C. Chem. Commun. 2013, 49, 8931. (b) Brice, H.; Gill, D. M.; Goldie, L.; Keegan, P. S.; Kerr, W. J.; Svensson, P. H. Chem. Commun. 2012, 48, 4836.

(23)Kalepu, J.; Katukojvala, S. Angew. Chem. Int. Ed. 2016, DOI:10.1002/anie.201600878.

(24)Ma, X.; Pan, S.; Wang, H.; Chen, W. Org. Lett. 2014, 16, 4554.

(25)Zulys, A.; Dochnahl, M.; Hollmann, D.; Loehnwitz, K.; Herrmann, J.-S.; Roesky, P. W.; Blechert, S. Angew. Chem. Int. Ed. 2005, 44, 7794.

(26)Arai, M. A.; Kuraishi, M.; Arai, T.; Sasai, H. J. Am. Chem. Soc. 2001, 123, 2907

(27)Gockel, B.; Krause, N. Org. Lett. 2006, 8, 4485.

(28)Zriba, R.; Gandon, V.; Aubert, C.; Fensterband, L.; Malacria, M. Chem.-Eur. J. 2008, 14, 1482.

(29)(a) Alcaide, B.; Almendros, P.; Carrascosa, R.; Martínez del Campo, T. Chem.-Eur. J. 2010, 16, 13243. (b) Alcaide, B.; Almendros, P.; Martinez del Campo, T.; Soriano, E.; MarcoContelles, J. L. Chem.-Eur. J. 2009, 15, 9127.

(30)Pawliczek, M.; Schneider, T. F.; Maass, C.; Stalke, D.; Werz, D. B. Angew. Chem. Int. Ed. 2015, 54, 4119.

(31)Trost, B. M.; Ashfeld, B. L. Org. Lett. 2008, 10, 1893.

(32)Trost, B. M.; Frontier, A. J.; Thiel, O. R.; Yang, H.; Dong, G. Chem.-Eur. J. 2011, 17, 9762.

(33)Liao, X.; Zhou, H.; Wearing, X. Z.; Ma, J.; Cook, J. M. Org. Lett. 2005, 7, 3501.

(34)Sawama, Y.; Sawama, Y.; Krause, N. Org. Biomol. Chem. 2008, $6,3573$. 